\title{
Role of Oyster Mushroom (Pleurotus ostreatus) Against Cecal Coccidiosis in Cobb 500 Broiler Chicken
}

\author{
M. Z. Hossain ${ }^{1}$, S. Akter ${ }^{1}$, M. A. H. N. A. Khan ${ }^{2}$, M. M. Ashraf ${ }^{2}$, and M. K. Islam ${ }^{1^{*}}$ \\ ${ }^{1}$ Department of Physiology, Faculty of Veterinary Science, Bangladesh Agricultural University, \\ Mymensingh-2202, Bangladesh \\ ${ }^{2}$ Deapartment of Pathology, Faculty of Veterinary Science, Bangladesh Agricultural University, \\ Mymensingh-2202, Bangladesh
}

Received 18 October 2012, accepted in revised form 11 December 2012

\begin{abstract}
A total of 25 day old Cobb 500 broiler chicks were purchased and randomly divided into five groups (A, B, C, D and E). Group A served as noninfected, non-supplemented control. Group B were infected and non-supplemented while chicks of group C, D and E were supplemented oyster mushroom (Pleurotus ostreatus) @ 50, 100 and $150 \mathrm{mg} / \mathrm{kg}$ body weight respectively with feed from 2-28 day of age. The chicks of group B, C, D and E were challenged orally with $1 \times 10^{4}$ sporulated oocysts of Eimeria tenella on $10^{\text {th }}$ day. The anticoccidial efficacy of oyster mushroom was evaluated based on oocysts counts per gram (OPG) of feces, weight gain, morbidity and mortality, necropsy findings and histopathology. Concerning the mean OPG count, body weight gain $(p<0.01)$, morbidity and mortality the highest performance $(p<0.01)$ was detected in group $\mathrm{D}$ and $\mathrm{E}$ on day 28 among the supplemented groups whereas group B showed the lowest performance. Group D and $\mathrm{E}$ showed the best results in regards of body weight, OPG counts, morbidity, mortality and post mortem findings as compared to healthy control (group A). So it could be concluded that supplementation of $100-150 \mathrm{mg}$ oyster mushroom/ $\mathrm{kg}$ body weight reduces the development of cecal coccidiosis in chicken.
\end{abstract}

Keywords: Oyster mushroom; Eimeria tenella; OPG; Body weight; Morbidity; Mortality.

(c) 2013 JSR Publications. ISSN: 2070-0237 (Print); 2070-0245 (Online). All rights reserved. doi: http://dx.doi.org/10.3329/jsr.v5i1.12229 $\quad$ J. Sci. Res. 5 (1), 185-193 (2013)

\section{Introduction}

Cecal coccidiosis is a common and fatal disease in poultry caused by Eimeria tenella. Though anticoccidial drugs will remain important for a long time but resistance development could limit their use [1]. Moreover, the price of synthetic anticoccidials is

\footnotetext{
*Corresponding author: k_islam88@yahoo.co.in
} 
too much high and efficacy is not so satisfactory. So, it is high time for the researchers to find out the effective immunomodulatory anticoccidial agent against coccidiosis that could be used to prevent coccidiosis.

In Asia and some tropical countries of Africa, edible and medicinal mushrooms such as Pleurotus ostreatus and Ganoderma lucidum are used as food supplements and medicines to improve various parameters of human health and immune functions in certain disease conditions [2,3]. Many literatures are available on the beneficial effects of mushrooms; particularly on the oyster mushroom (Pleurotus ostreatus), which is very common in Bangladeah. Mushrooms, like probiotics are natural ingredients that contain bioactive chemical substances, polysaccharides, proteins, crude fibers, unsaturated fat, minerals, vitamins, essential amino acids and organic acids that can be used as good sources of food supplements and medicines to promote health and production $[4,5]$. They stabilize microflora in the gastrointestinal tract, and prevents colonization of host cells by pathogens and also stimulates non-specific host immune response or phagocytosis by macrophages [6]. There has been a recent upsurge of interest in mushrooms not only as a health food which is rich in protein [7] but also as a source of biologically active compounds of medicinal value which include complementary medicine/dietary supplements for anticancer [8], antioxidant [9], antimicrobial [10], antiviral [11, 12], antiinflammatory [13, 14], antiallergic [15], hepatoprotective [16], immunopotentiating [17] and hypocholesterolemic $[18,19]$ agents. Mushrooms also contain a spectrum of nutrients at varied levels, such as B vitamins, vitamin D, and minerals (potassium, copper, magnesium, selenium, and zinc) [20]. Already it has been reported that ethanolic mycelial extracts from Lentinus edodes possess antiprotozoal activity [21] and aqueous extract of a wild mushroom Ganoderma lucidum has anticoccidial effect against Eimeria tenella giving positive impact on weight, fecal oocyst count and packed cell volume [4]. However, the mechanisms of the various health benefits of mushrooms to poultry still require intensive investigation, especially given the emergence of new evidence of their health benefits like anticoccidial role. From this point of view the present study was conducted to evaluate the role of oyster mushroom supplementation at different doses against cecal coccidiosis in Cobb 500 broiler.

\section{Materials and Methods}

\subsection{Experimental protocol and diets}

To conduct the experiment, a number of 25 day old of Cobb 500 broiler chicks were collected from local market and equally divided into five groups (group A, B, C, D and E), each of which containing 5 chicks.

Chicks of group A were maintained as noninfected, non-supplemented control. Chicks of group B were infected and non-supplemented whereas chicks of group C, D and E served as supplemented groups. Dried oyster mushroom (Pleurotus ostreatus) was 
collected from Horticulture Center, BAU First Gate, Mymensingh. The Dried mushroom was grinded to turn it into powder form. From day 2 up to day 28 of age, chicks of group $\mathrm{C}, \mathrm{D}$ and $\mathrm{E}$ were supplemented with oyster mushroom powder at a dose rate of 50, 100 and $150 \mathrm{mg} / \mathrm{kg}$ body weight respectively with feed. Body weight of chickens was recorded on weekly basis. Oocyst per gram (OPG) of feces was counted following McMaster technique on day 28 of age of the chickens. Post-mortem examinations of the broilers were performed at the end of experiment (day 28). Ceca, intestine, liver and spleen were examination. The gross post-mortem findings of these organs were recorded.

\subsection{Histology}

The ceca was excised from each bird, immersed in chilled phosphate-buffered saline and blotted dry. A $4 \mathrm{~mm}$ section of the ceca was placed into a histological cassette. The cassette containing the cecal section of each bird was individually immersed in a $10 \%$ (v/v) buffered formalin phosphate solution for fixing and subsequent staining. The formalin-fixed, paraffin-embedded tissue samples were ultrasectioned (4-5 $\mu \mathrm{m}$ thickness), stained with hematoxylin and eosin and examined under a light microscope (Olympus).

\subsection{Statistical analysis}

All data were expressed as mean $\pm \mathrm{SE}$, group mean values of weight gain and oocysts output of the chicks were compared by ' $\mathrm{t}$ ' test with $\mathrm{N},+\mathrm{N} 2-2$ degrees of freedom. Statistical significance was set at $p<0.05$. Statistical analysis was performed using SPSS software version 17 (SPSS Inc., Chicago, IL, USA).

\section{Results}

\subsection{Body weight records}

The impact of oral administration of dietary supplementation of oyster mushroom on body weight of different groups of chickens followed by administration of sporulated coccidial oocysts are represented in the Table 1 . The mean initial weight of chicks for all groups was almost similar which was recorded on day 1 . The highest body weight was recorded on day 28 in group A (control healthy). Among the supplemented groups the highest significant $(p<0.01)$ body weight gain was recorded in group E on 4 weeks of age following supplementation $(150 \mathrm{mg} / \mathrm{kg})$ and administration of coccidial oocysts. Chickens of group D $(100 \mathrm{mg} / \mathrm{kg})$ gained the next highest $(p<0.01)$ body weight on the same day. The challenged control group (group B) had the least minimum body weight $(p<0.01)$ on 4 weeks of age. 
Table 1. Body weight gain of chicken after mushroom supplementation (day 2 to day 28) and oocysts challenge (on day 10).

\begin{tabular}{lccccc}
\hline Groups & \multicolumn{5}{c}{ Body weight records (g) } \\
\cline { 2 - 6 } & Day 1 & $\begin{array}{c}\text { 1st } \\
\text { week }\end{array}$ & $\begin{array}{c}\text { 2nd } \\
\text { week }\end{array}$ & $\begin{array}{c}\text { 3rd } \\
\text { week }\end{array}$ & $\begin{array}{c}\text { 4th } \\
\text { week }\end{array}$ \\
\hline Group A (control & 37.36 & 154.71 & 434.99 & 723.35 & 1053.37 \\
noninfected) & \pm 0.51 & $\pm 1.89^{\mathrm{NS}}$ & $\pm 1.82^{* *}$ & $\pm 1.81^{\mathrm{NS}}$ & $\pm 2.18^{* *}$ \\
\hline Group B & 37.91 & 153.17 & 420.66 & 590.28 & 650.10 \\
(control infected) & \pm 0.47 & $\pm 2.49^{\mathrm{NS}}$ & $\pm 1.17^{* *}$ & $\pm 1.47^{* *}$ & $\pm 1.76^{* *}$ \\
\hline Group C (50 mg & 38.07 & 161.38 & 441.68 & 627.09 & 948.02 \\
mushroom $/ \mathrm{kg})$ & \pm 0.40 & $\pm 0.91^{*}$ & $\pm 1.32^{*}$ & $\pm 1.51^{* *}$ & $\pm 1.12^{*}$ \\
\hline Group D $(100 \mathrm{mg}$ & 37.97 & 167.37 & 460.46 & 720.23 & 1017.76 \\
mushroom/kg) & \pm 0.61 & $\pm 1.35^{* *}$ & $\pm 1.39^{* *}$ & $\pm 1.77^{\mathrm{NS}}$ & $\pm 2.50^{* *}$ \\
\hline Group E (150 mg & 38.43 & 165.22 & 460.22 & 718.51 & 1018.32 \\
mushroom/kg) & \pm 0.68 & $\pm 1.06^{*}$ & $\pm 1.37^{* *}$ & $\pm 2.03^{\mathrm{NS}}$ & $\pm 1.36^{* *}$ \\
\hline
\end{tabular}

Values represent the mean \pm standard error (SE) of the body weight of chickens of different groups $(n=5) ;{ }^{* *}=$ Significant at $1 \%$ level $(p<0.01) ; *=$ Significant at $5 \%$ level $(p<0.05)$; NS

$=$ Non significant.

\subsection{Oocyst per gram (OPG) counts}

The OPG counts of different groups of chickens are represented in the Table 2. The highest oocysts counts per gram (OPG) of feces was recorded in group B as it was untreated control group. The lowest OPG was recorded in group D, which supplemented with $100 \mathrm{mg}$ oyster mushroom/kg body weight. The OPG count of group E (supplemented with $150 \mathrm{mg}$ oyster mushroom/kg body weight) the second lowest value. Remaining group C supplemented with $50 \mathrm{mg}$ oyster mushroom/kg body weight recorded the highest OPG value (5.94 \pm 0.67$)$ among the supplemented groups.

Table 2. OPG count (thousand) on day 28 (post-infection).

\begin{tabular}{lc}
\hline Groups & $\begin{array}{c}\text { OPG count (thousand) } \\
\text { on day } 28\end{array}$ \\
\hline Group A (control noninfected) & 0 \\
Group B (control infected) & $58.05 \pm 2.46$ \\
Group C (50 mg mushroom $/ \mathrm{kg})$ & $5.94 \pm 0.67$ \\
Group D (100 mg mushroom $/ \mathrm{kg})$ & $0.03 \pm 0.00$ \\
Group E (150 mg mushroom $/ \mathrm{kg})$ & $0.04 \pm 0.00$ \\
\hline
\end{tabular}

The above values represent the mean \pm standard error (SE) of OPG of chickens of different groups $(n=5)$. 


\subsection{Morbidity and mortality records}

By the end of the experiment (day 28), a total of 10 broiler chicks were affected with illhealth and 4 chicks died as a result of infection with cecal coccidiosis. All chicks of challenged control group (group B) were affected with cecal coccidiosis, and among them 3 chicks were died indicating $100 \%$ morbidity and $60 \%$ mortality. In group C, 3 chicks were affected out of which only one died indicating $60 \%$ morbidity and $20 \%$ mortality. One chick each from group D and E (20\% morbidity) showed signs of cecal coccidiosis but none of the birds died (no mortality). No bird was affected from the group A (healthy control).

\subsection{Gross postmortem findings}

Group A appeared healthy through-out the study and lesions were not observed in any part of gastrointestinal tract as well as other vital organs. The ceca of group B was slightly pale, and the wall showed patchy hemorrhage (Fig. 1). All other vital organs appeared normal but the liver was slightly pale. In group $\mathrm{C}$ there was also blood tinged contents in the ceca and hemorrhages found on cecal wall (Fig. 1) but the severity was less than that of group B. All other organs were apparently uninfected and normal. No significant change was observed in ceca and all other part of intestine of group D and E as well as other organs including liver, lung, kidney, spleen, bursa, and thymus.
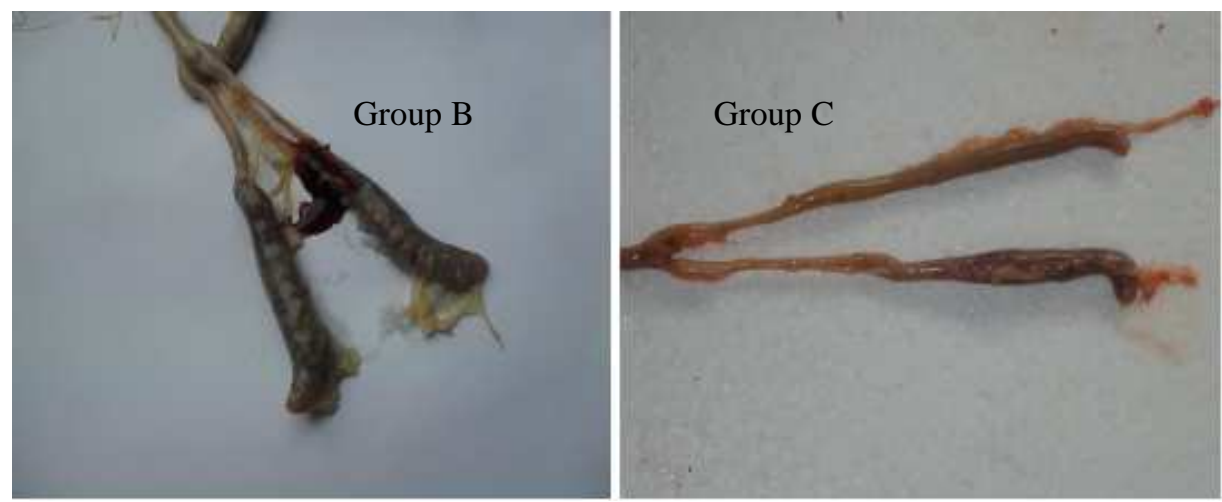

Fig. 1. Distended ceca filled with blood tinged contents with patchy hemorrhage of a dead bird of group B on day 24. Ceca of group $\mathrm{C}$ on day 28 with few blood tinged contents.

\subsection{Histopathological studies}

Histopathological analysis of ceca through H\&E and staining showed marked differences between the groups studied. In group A (control noninfected) the ceca showed almost 
normal structure (Fig. 2). The microscopic lesions of the chicks of group B consisted of slight thickening of the villi due to infiltration of mononuclear cells and eosinophils in lamina propria (Fig. 2) of the ceca. In group C there were erosion and desquamation of crypt epithelia, infiltration of reactive cells in the lamina propria (Fig. 2). Merozoites/schizonts were also found in the crypt of villi. The ceca of group D showed infiltration of inflammatory cells (Fig. 2) indicating diffuse acute cecitis. In group E the ceca showed almost normal structure as in group A in which the histopathology of ceca did not reveal any significant lesion related to coccidiosis but little infiltration of reactive cells in the lamina propria (Fig. 2).

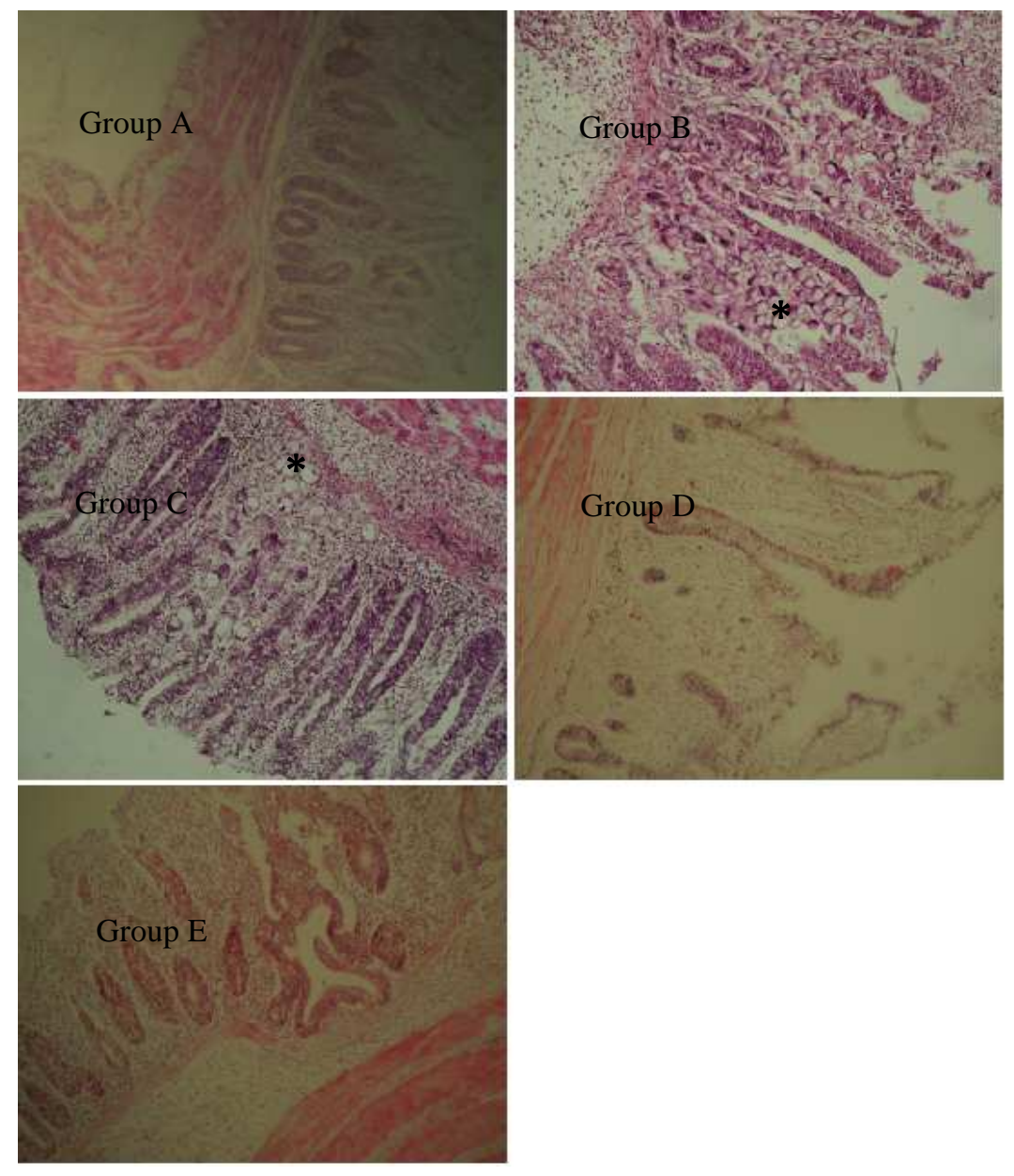

Fig. 2. Micrographs of cecal section of the chicken (H\&E stain). Photographs were taken under microscope (Olympus) at X 33 magnification. Group A (healthy control) showing normal structure. Group B (infected control) showing desquamation of cecal epithelia, merozoites/schizont in the cecal crypt and infiltration of reactive cells in the mucosa and submucosa (astaric mark). 
Group $\mathrm{C}$ showing erosion and desquamation of crypt epithelia, infiltration of reactive cells in the lamina propria of cecal section. Merozoites/schizonts were also found in the crypt of villi (astaric mark). Group D showing defuse infiltration of inflammatory cells indicating diffuse acute caecitis and group E showing little infiltration of reactive cells in the lamina propria.

\section{Discussion}

We have investigated the anticoccidial efficacy of oyster mushroom in relation to OPG of feces, weight gain, morbidity and mortality, necropsy findings and histopathology. After completing the trials successfully, the group $\mathrm{D}$ and $\mathrm{E}$ among the groups of supplementation provided the best result on the basis of body weight, OPG counts, postmortem examination which was very close to the records of group A (control noninfected). Our study suggests that oyster mushroom powder supplementation can prevent low growth rate of broilers due to coccidial oocyst ingestion in chickens. These findings have close agreement with the reports of another author [4] who studied oral treatment of Eimeria tenella-infected broilers using aqueous extract of wild mushroom (Ganoderma $\mathrm{sp}$ ) and found considerable weight variations. Similar report was found in a study on anti-inflammatory activity of edible oyster mushroom [22]. They reported that oyster mushroom (Pleurotus ostreatus) has significant anti-inflammatory effect which is mediated through the inhibition of NF- $\kappa \mathrm{B}$ and AP-1 signaling. Already it has been reported that ethanolic mycelial extracts from Lentinus edodes possess antiprotozoal activity [21]. The lowest OPG was recorded in $100 \mathrm{mg}$ oyster mushroom $/ \mathrm{kg}$ body weight supplemented group indicating the highest prophylactic efficacy among all of the groups. In conformity to the present findings, a report was found in a study of oral treatment of Eimeria tenella-infected broilers using aqueous extract of wild mushroom (Ganoderma sp.) [4] and found similar OPG values. It has been found that the antiallergic potentials of some Japanese edible mushrooms [15] and found that ethanolic extracts of the edible Japanese basidiomycetes H. marmoreus, F. velutipes, Pholiota nameko and Pleurotus eryngii show significant antiallergic effects in mice (oxazolone-induced type IV allergy) also after oral application. No remarkable information has been found regarding morbidity and mortality following mushroom supplementation and oocyst challenging in chickens. It has also been stated that mushroom represent an unlimited source of polysaccharides which induce antitumor and immunostimulating properties [23]. The immunobiology of mushroom was studied by other authors [24] who reported that mushrooms have beneficial effects on immune function with subsequent implications for inhibition of tumor growth.

Microscopic lesion related with cecal coccidiosis was not seen in noninfected control group. In infected control group the cecal glands of the crypt region contain mucous exudates in the lumen. Merozoites/schizonts were found in contact with villi and crypt epithelium. Inflammation preceded further additional hemorrhage in the lamina propria and submucosa. Desquamation of crypt epithelia was found. The histopathological studies have the agreements with the researchers [25] who studied oral treatment of Eimeria 
tenella-infected broilers using aqueous extract of wild mushroom (Ganoderma sp.) and found mild lymphocytic infiltration in the liver of the broilers. They also concluded that the mushroom has no deleterious or adverse effects on the organs of treated birds.

\section{Conclusion}

From the present research it could be concluded that $100-150 \mathrm{mg}$ oyster mushroom powder supplementation/kg body weight would be the best prophylactic solution against cecal coccidiosis than other doses. This study also suggests that oyster mushroom powder supplementation can prevent low growth rate of broilers due to coccidial oocyst ingestion in chickens. There is not any significant adverse effect in chicken due to this type of supplementation as no remarkable lesion was recorded in liver, spleen, bursa and thymus. However, in this study only one species of Eimeria (E. tenella) oocysts was used. So, further study is needed to determine the prophylactic efficacy of oyster mushroom against other species of Eimeria and these researches would provide a clear idea on the efficacy of oyster mushroom against chicken coccidiosis.

\section{Acknowledgement}

This work was supported by the National Science and Technology (NST) funded by the Ministry of Science and Technology (MOST), People's Republic of Bangladesh.

\section{References}

1. B. Stephen, M. Rommel, A. Dangschies and A. Haberkorn, Vet. Parasitol. 69, 19 (1997). http://dx.doi.org/10.1016/S0304-4017(96)01096-5

2. M. M. Anthony and C. Joyce, Afr. J. Food Agric. Nutr. Dev. 7, 1 (2007).

3. S. T. Chang and K. E. Mshigeni, The University of Namibia, Windhoek, 1-79, 1188 (2001).

4. A. O. Ogbe, S. E. Atawodi, P. A. Abdu, A. Sannusi and A. E. Itodo, J. South African Vet. Assoc. 80, 97 (2009). http://dx.doi.org/10.4102/jsava.v80i2.179

5. S. Wachtel-Galor, B. Tomlinson and I. F. Benzie, Brit. J. Nutr. 91, 263 (2004). http://dx.doi.org/10.1079/BJN20041039

6. F. C. Guo, H. F. J. Savelkoul, R. P. Kwakkel, B. A. Williams and M. W. A. Verstegen, World's Poult. Sci. J. 59, 427 (2003). http://dx.doi.org/10.1079/WPS20030026

7. L. Barros, T. Cruz, P. Baptista, L. M. Estevinho and I. C. Ferreira, Food Chem Toxicol. 46, 2742 (2008). http://dx.doi.org/10.1016/j.fct.2008.04.030

8. L. M. Cheung, P. C. K. Cheung, and V. E. C. Ooi, Food Chem. 81, 249 (2003). http://dx.doi.org/10.1016/S0308-8146(02)00419-3

9. S. T. Chang and P. G. Miles, Boca Raton (FL: CRC Press, 2004) pp. 27-38.

10. U. Lindequist, E. Teuscher and G. Narbe, Phytother. Res. 11, 139 (1990).

11. C. R. Brandt and F. Piraino, Recent Res Dev Antimicrob Agents Chemother. 4, 11 (2000).

12. R. A. A. Mothana, N. A. A. Awadh, R. Jansen, U. Wegner, R. Mentel, and U. Lindequist, Fitoterapia. 74, 177 (2003). http://dx.doi.org/10.1016/S0367-326X(02)00305-2

13. G. Y. Kim, S. H. Kim, S. Y. Hwang, H. Y. Kim, Y. M. Park, and S. K. Park, Biol. Pharm. Bull. 26, 823 (2003). http://dx.doi.org/10.1248/bpb.26.823

14. S. H. Kim, Y. S. Song, S. K. Kim, B. C. Kim, C. J. Lim, and E. H. Park, J Ethnopharmacol. 93, 141 (2004). http://dx.doi.org/10.1016/j.jep.2004.03.048 
15. M. Sano, K. Yoshino, T. Matsuzawa, and T. Ikekawa, Int. J. Med. Mushrooms 4, 37 (2002). http://dx.doi.org/10.1615/IntJMedMushr.v4.i1.40

16. M. Y. Wang, Q. Liu, Q. M. Che, and Z. B. Lin, Int. J. Med. Mushrooms 4, 337 (2002).

17. S. V. Reshetnikov, S. P. Wasser, and K. K. Tan, Int. J. Med. Mushrooms 3, 361 (2001).

18. Y. Ishikawa, K. Marimoto, and T. Hamasaki, J. Am. Oil Chem. Soc. 61, 1864 (1984). http://dx.doi.org/10.1007/BF02540819

19. F. Tokita, N. Shibukawa, T. Yasumoto, and T. Kaneda, Mushroom Sci. 8, 783 (1972).

20. P. Mattila, K. Konko, M. Euvola, J. Pihlava, J. Astola, and L. Vahteristo, J. Agr. Food Chem. 42, 2449 (2001).

21. S. M. Badalyan, Int. J. Med Mushrooms 6, 131 (2004). http://dx.doi.org/10.1615/IntJMedMushr.v6.i2.40

22. A. Jedinak, S. Dudhgaonkar, Q. Wu, J. Simon, and D. Sliva, J. Nutr. 10, 52 (2011). http://dx.doi.org/10.1186/1475-2891-10-52

23. S. Wasser, Appl. Microbiol Biot. 60, 258 (2002). http://dx.doi.org/10.1007/s00253-002-1076-7

24. A. T. Borchers, A. Krishnamurthy, C. L. Keen, F. J. Meyers, and M. E. Gershwin, Exp. Biol. Med. 233, 259 (2008). http://dx.doi.org/10.3181/0708-MR-227

25. A. O. Ogbe, S. E. Atawodi, P. A. Abdu, B. O. Oguntayo, and N. Dus, Afr. J. Biotechnol. 9, 8923 (2010). 